\title{
Does the cowl make the monk? Detecting counterfeits in brand names versus logos
}

\author{
Manuel Perea ${ }^{1,2} \cdot$ Ana Baciero $^{2,3} \cdot$ Francisco Rocabado $^{2} \cdot$ Ana Marcet $^{1}$ \\ Accepted: 11 December 2020 / Published online: 9 February 2021 \\ (C) The Psychonomic Society, Inc. 2021
}

\begin{abstract}
Companies and products are identified by their brand names, which are typically written with a specific letter style, color, and design (i.e., logos). This graphical information offers a distinctive image that facilitates their recognition. However, the uniqueness of these configuration cues may make brand names more vulnerable to counterfeiting via misspelling. We examined whether the confusability at detecting misspelled brand names is higher when embedded in the full logo than when presented in plain format (Experiment 1), when removing all graphical information of the logo other than typeface (Experiment 2), and when only modifying the typeface (Experiment 3 ). Participants had to decide whether the presented item was a correctly spelled brand name. The misspelled stimuli were created by either transposing or replacing two internal letters of popular brand names (amazon $\rightarrow$ amzaon vs. amceon), thus allowing us to have a measure of the transposed-letter confusability effect. Results showed a sizeable transposed-letter confusability effect for all types of brand names, but the effect was greatest for the misspelled full logos. Thus, the distinctiveness of the graphical information in logos has a deleterious side effect: logos are quite vulnerable to counterfeiting via misspelling branding.
\end{abstract}

Keywords Transposed-letter confusability effect $\cdot$ Word recognition $\cdot$ Logos $\cdot$ Marketing

When we walk down a main street or surf the internet, we are surrounded by countless logos, each with its own design. Marketing design experts make strong efforts to create distinctive logos that represent an entity, organization, or product. Logos can be classified into two categories: logotypes and logomarks. Logotypes are stylish versions of the brand name with a consistent typeface, design, and color (e.g., the Coca-Cola logo), whereas logomarks only use a symbol or image (e.g., the Apple logo). Logos frequently combine logotypes and logomarks (e.g., the McDonald's logo).

Ana Baciero

abaciero@nebrija.es

1 Universitat de València, Valencia, Spain

2 Universidad Antonio de Nebrija, Madrid, Spain

3 DePaul University, Chicago, USA
The examination of how we identify brand names and logos is important from both applied and theoretical sides. From an applied side, the trade of counterfeit goods is more than 3\% of world trade in 2019 (OECD, 2019). With the aim to deceive potential buyers, many counterfeits are created by slightly modifying the spelling of popular brand names (e.g., Mcdnoald's, adadis, SQNY) while keeping a similar typeface, layout/color, so the resulting items can be easily mistaken for the original products. ${ }^{1}$ Indeed, it has been estimated that around $20 \%$ of customers unintentionally buy items that look like an original brand (Clear, 2013). To protect their own products, companies sue other companies with lookalike products over trademark infringement. For instance, John Lennon's wife, Yoko Ono, sued the company responsible for the John Lemon drink (Butler, 2017) because $m$ and $n n$ are visually similar (Marcet \& Perea, 2018). However, these

\footnotetext{
${ }^{1}$ We acknowledge that some counterfeits may imitate the theme rather than the features (see van Horen \& Pieters, 2012). Using the idea of brand name parodies in The Simpsons (see Qiao, Chicotsky, \& Billings, 2016), Krusty Burger would be a thematic imitation of Burger King or McDonald's, whereas Mapple Store would be a feature imitation of Apple Store.
} 
legal battles are complicated, especially in those countries with lenient trademark infringement laws (Chang, 2014). To make matters more difficult, there are no consensual criteria to decide whether two brand names are potentially confusable. As Abdel-Khalik (2007) discussed in the context of U.S. courts, LEXIS was allowed to coexist with LEXUS, whereas POLARAID lost the legal battle with POLAROID — in both examples, the brand names differ by just one letter.

From the theoretical side, brand names and logos represent a very special type of printed stimuli for reading research. As Gontijo and Zhang (2007) indicated, brand names are less specific than proper names, but more specific than common nouns. More important for the present purposes, brand names provide consistent visual information: They are typically presented with the same letter-case configuration (e.g., IKEA, adidas). Indeed, brand names are identified faster when presented in their typical letter-case configuration (e.g., adidas faster than ADIDAS; IKEA faster than ikea; Gontijo \& Zhang, 2007; Perea, Jiménez, Talero, \& López-Cañada, 2015). This pattern is consistent with the notion that readers may use orthographic cues like letter case to access the mental lexicon (see Peressotti, Cubelli, \& Job, 2003, for evidence with proper nouns).

Furthermore, to make brand names more identifiable and distinctive, companies use logotypes (i.e., brand names using a specific typeface, color, and design; see Foroudi, Melewar, \& Gupta, 2017, for a historical review). Thus, when we encounter a logo, we encode not only the identity/position of each letter (see Davis, 2010, for a computational model of visual-word recognition), but also its characteristic graphical features (i.e., typeface, color, and design). The idea is that the repeated encounter of a well-designed logo would make the whole percept easily recognizable (e.g., Spencerian lettering $\rightarrow$ Coca-Cola). Indeed, young children can identify popular logos (e.g., Coca-Cola) before learning to read, but fail to identify them when presented in plain format (Kuby, Aldridge, \& Snyder, 1994; Masonheimer, Drum, \& Ehri, 1984).

Rather surprisingly, there has been very little research in cognitive psychology that examines the processes underlying the identification of logotypes with adult readers (see Blake, Nazarian, \& Castel, 2015, for recent research on logomarks). Two exceptions are the recent studies conducted by Pathak, Velasco, and Calvert (2019a, 2019b) in which participants had to decide whether a logotype was correctly spelled or not. In Experiment 1, Pathak et al. (2019a) employed seven logos (e.g., the facebook logo) that could be presented in their original form or with a transposition of the two initial or the two final letters (afcebook and faceboko; i.e., the misspelled logos). They found longer response times and higher error rates when the misspelled logo had the initial letter transposed than when it had its final letter transposed. Pathak et al.'s (2019a) Experiment 2 replicated this pattern when the misspelled logos were created by replacing the initial or the final letter (tacebook vs. facebooa). Furthermore, Pathak et al. (2019b) created, by letter transposition/migration, three types of misspelled logos varying in their orthographic similarity with the original (e.g., facbeook vs. fcabeook vs. fcbaoeok). Results showed longer response times and more errors for "close" misspelled logos (e.g., facbeook) than for "distant" misspelled logos (e.g., fcbaoeok).

Taken together, the findings from Pathak et al. (2019a, 2019b) extended, using logos, earlier research conducted with common words. First, changes in the initial letter position are more noticeable than changes in the final letter position (Scaltritti, Dufau, \& Grainger, 2018; Tydgat \& Grainger, 2009). Second, transposed-letter items are perceptually similar to the original items, and this is especially the case for internal letter positions (O'Connor \& Forster, 1981; see Grainger, 2018, for a recent review). And third, transposed-letter items are more confusable when they involve close rather than distant transpositions (Perea, Duñabeitia, \& Carreiras, 2008).

Clearly, the Pathak et al. (2019a, 2019b) experiments revealed important similarities between the identification of logos and the identification of common words. However, there are still some relevant questions to be addressed regarding how we process logos (either correctly spelled or misspelled). To what degree does graphical information modulate the ability to distinguish authentic from misspelled brand names? Furthermore, marketing experts have frequently claimed that letter style in a logo expresses the visual identity of a brand name (e.g., the Spencerian lettering in Coca-Cola; see Foroudi et al., 2017). Thus, what is the role of letter style in the identification of a logo? As indicated above, research with prereaders found dramatic differences between the processing of logos and the processing of plain brand names. While one should be cautious of interpreting the data from prereaders (see Share \& Gur, 1999), what is certain is that logos contain very distinctive information (i.e., typeface, color, layout/design) in addition to orthographic information (i.e., letter identity and position). For common words, theorists have proposed a number of computational models of visual-word recognition that successfully capture many benchmark effects (see Davis, 2010); however, at present, there are no extant models on how logos are identified.

Thus, the main goal of the present experiments is to examine the role of the graphical information of logos on the detection of misspelled brand names. In Experiment 1, we compared the participants' performance at detecting misspelled brand names presented as full logos (i.e., the logo with all its graphical features) or as plain brand names (i.e., the logo's name without its corresponding graphical information). We replaced the plain format with a logo condition that removed all graphical elements except its letter style in Experiment 2 ("typeface-only" logos) and with a logo condition that kept all the graphical elements of the logo while modifying its 
typeface in Experiment 3 ("different typeface" logo; see Fig. 1 , for illustration). In all experiments, half of the trials involved the correctly spelled items and the other half involved misspelled items. For the misspelled stimuli, we transposed two internal letters of the brand name (e.g., amazon $\rightarrow$ amzaon). To act as orthographic controls, we replaced the two letters that were transposed in the above condition (e.g., amceon), while controlling for consonant/vowel status and bigram frequency (see Perea \& Lupker, 2004, for explanation for the need of this orthographic control). The transposed-letter confusability effect is the difference in performance between the transposed-letter condition and the replacement-letter condition: the higher the confusability, the higher the magnitude of the transposed-letter effect.

In sum, we designed three experiments to examine the following question: Does the graphical information of logos increase the perceptual confusability of their misspelled counterparts? And, more specifically, what is the role of letter style in the identification of a logo? To do so, we employed a task that only required the use of orthographic information and in which the presence of graphical information was not diagnostic of the responses (i.e., "Is the brand name correctly spelled?"). Therefore, if graphical information of the items (irrelevant to the task) makes misspelled logos more confusable with the originals than their plain, unformatted counterparts, one would expect a greater transposed-letter confusability effect for the former. This outcome would reveal that graphical information plays a major role at identifying logos. At the practical side, this pattern would suggest that the distinctiveness of logos has a weak spot: it can be used by counterfeits aiming to deceive customers. Alternatively, if logos are processed just as plain brand names, one would expect a similar transposed-letter confusability effect for all misspelled formats. This would suggest that, at least in an orthographically based task, the graphical features of the logos do not alter the confusability of misspelled brand names.

\section{Experiment 1}

\section{Method}

\section{Participants}

The sample was composed of 30 undergraduate students of the University of Valencia. With this sample size, we had 1,800 observations in each of the "format/type of stimulus" combinations. In this and the following experiments, participants signed an informed consent before the experiment. None of the participants reported having any reading problems.

\section{Materials}

We selected 15 well-known logotypes in Spain (amazon; SAMSUNG; LACOSTE; DISNEY; Levi's; Colgate; Google; NESCAFÉ; BURGER KING; STARBUCKS COFFEE; FANTA; intel; Movistar; Estrella Galicia; MERCADONA). For each item, we created two misspelled versions: (1) a transposedletter (TL) misspelled item, in which we transposed two adjacent letters (e.g., amzaon); (2) a replacement-letter (RL) misspelled item, in which we replaced the two consonants that had been transposed with two other letters (e.g., amceon; see Fig. 1). The two sets of misspelled items were matched in mean log bigram

Full Logo (Experiments 1-3)

\section{amazon amzaon amceon}

Plain brand name (Experiment 1)

\section{amazon amzaon amceon}

Typeface-only logo (Experiment 2)

amazon

Different typeface logo (Experiment 3)

\section{amzaon}

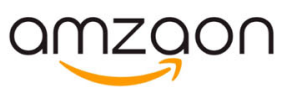

\section{amceon}

\section{amceon}

logo). The next three panels present their corresponding plain, typefaceonly, and different typeface versions.
Fig. 1 The top panel presents a brand name (amazon), a misspelled transposed-letter logo (amzaon), and a misspelled replacement-letter logo (amceon), the three of them embedded in amazon's original logo (i.e., full 
Table 1 Mean correct response times (in ms) and error rates (in percentage) for correctly spelled and misspelled brand names in Experiment 1

\begin{tabular}{lllll}
\hline & Correct brand name & Transposed-letter brand name & Replacement-letter brand name & Transposed-letter effect \\
\hline Format & & & & \\
Full logo & $768(4.0)$ & $870(23.3)$ & $716(4.1)$ & $154(19.2)$ \\
Plain & $764(5.7)$ & $796(16.9)$ & $672(2.9)$ & $124(14.0)$ \\
\hline
\end{tabular}

frequencies per million (1.659 vs. 1.664, for the TL and RL items, respectively, $t<1, p>.9$ ) in the Spanish database B-Pal (Davis \& Perea, 2005). The stimuli were presented as logos or as plain brand names in Times New Roman (we chose this font because none of the logos employs it). For the plain brand names, we always kept their typical letter-case configuration (see Gontijo \& Zhang, 2007; Perea et al., 2015). Because of the difficulties at creating the stimuli, each item was presented several times, following the Pathak et al. (2019a, 2019b) experimental design. ${ }^{2}$ The experimental list contained 240 correctly spelled trials (120 as logos, 120 in plain format) and 240 misspelled trials (120 transposed-letter items [60 as logos, 60 in plain format] and 120 replacement-letter items [60 as logos, 60 in plain format]).

\section{Procedure}

Participants were tested in groups of up to seven participants. DMDX software (Forster \& Forster, 2003) was used to present the stimuli and collect the participants' responses. The setup in each trial follows: A fixation point (+) was presented in the center of the computer screen for $500 \mathrm{~ms}$. Then, the target stimulus was presented until the participant responded or $2 \mathrm{~s}$ had passed. Participants were instructed to decide whether the stimulus on the screen was an authentic brand name (regardless of format) or not, while trying to keep a low error rate. The experimental phase, which was composed of 480 trials, was preceded by 15 practice items to familiarize the participants with the task - these items were either the correctly spelled or the misspelled version of the brand names. There were three short breaks every 120 trials. The order of the stimuli in the experimental phase was randomized for each participant. The whole session lasted 14-16 min.

\section{Results}

Incorrect responses and very short response times (less than $250 \mathrm{~ms}$ [three observations]) were removed from the latency analyses - failing to respond before the 2-s deadline was

\footnotetext{
${ }^{2}$ To create the replacement-letter stimuli, we only selected popular logos whose typeface was available. This posed some limits on the number of potential logos we could employ - we also avoided brand names of less than five letters (e.g., IKEA). Similar to the Pathak et al. (2019a) experiment with logos, the stimuli were repeated in the experiment. Of note, they successfully replicated several benchmarks effects in visual-word recognition with a smaller number of stimuli than in our experiments ( 7 vs. 15 base stimuli, respectively).
}

automatically categorized as an incorrect response. The mean response times and error rates in each experimental condition are displayed in Table 1. Consistent with our research question, we focused on the misspelled stimuli. ${ }^{3}$

To analyze the data, we created generalized linear mixedeffects models in $\mathrm{R}$ with the lme4 package (Bates, Maechler, Bolker, \& Walker, 2015) on the latency and accuracy data. For the latency data, we employed the gamma distribution with the identity link (see Yang \& Lupker, 2019)_-this avoids nonlinear transformations of the response times required by the normality assumption of linear mixed models. For the accuracy data, we employed the binomial distribution. The two fixed-effect factors were format (logo, plain) and type of stimulus (transposed-letter, replacement-letter). Each of these factors were centered-coded as -.5 and .5. We chose the maximal random factor structure model in terms of by-subjects and by-items intercepts and slopes that converged. The code used for these analyses is presented in the Appendix (see also https://osf.io/m34zf/ to access the stimuli, data sets, and code).

The analyses of the response times showed that transposedletter items were responded to more slowly than replacementletter items, $b=171.68, S E=4.18, t=41.05, p<.001$, and that misspelled full logos were responded to more slowly than the misspelled plain brand names, $b=-40.87, S E=4.19, t=$ $-9.75, p<.001$. Furthermore, the transposed-letter confusability effect was greater for misspelled full logos than for misspelled plain brand names (154 vs. $124 \mathrm{~ms}$, respectively; interaction: $b=-35.69, S E=4.12, t=-8.42, p<.001$; see Fig. 2a).

The analyses of the accuracy data showed that responses to transposed-letter items were less accurate than the responses to replacement-letter items, $b=-1.99, S E=0.29, z=-6.89, p$ $<.001$, and that responses to misspelled full logos were less accurate than the responses to misspelled plain brand names, $b$ $=0.38, S E=0.18, z=2.09, p=.037$. The interaction between the two factors was not significant, $t<1, p>.50$; note, however, that the accuracy followed the pattern as in the latency data (19.2\% vs. $14.0 \%$ of errors for misspelled full logos and misspelled plain brand names, respectively).

\footnotetext{
${ }^{3}$ We did not examine the effect of format (i.e., plain vs. logo) for the correctly spelled items because any potential differences in response time or error rates could be due to the familiarity of the fonts.
} 

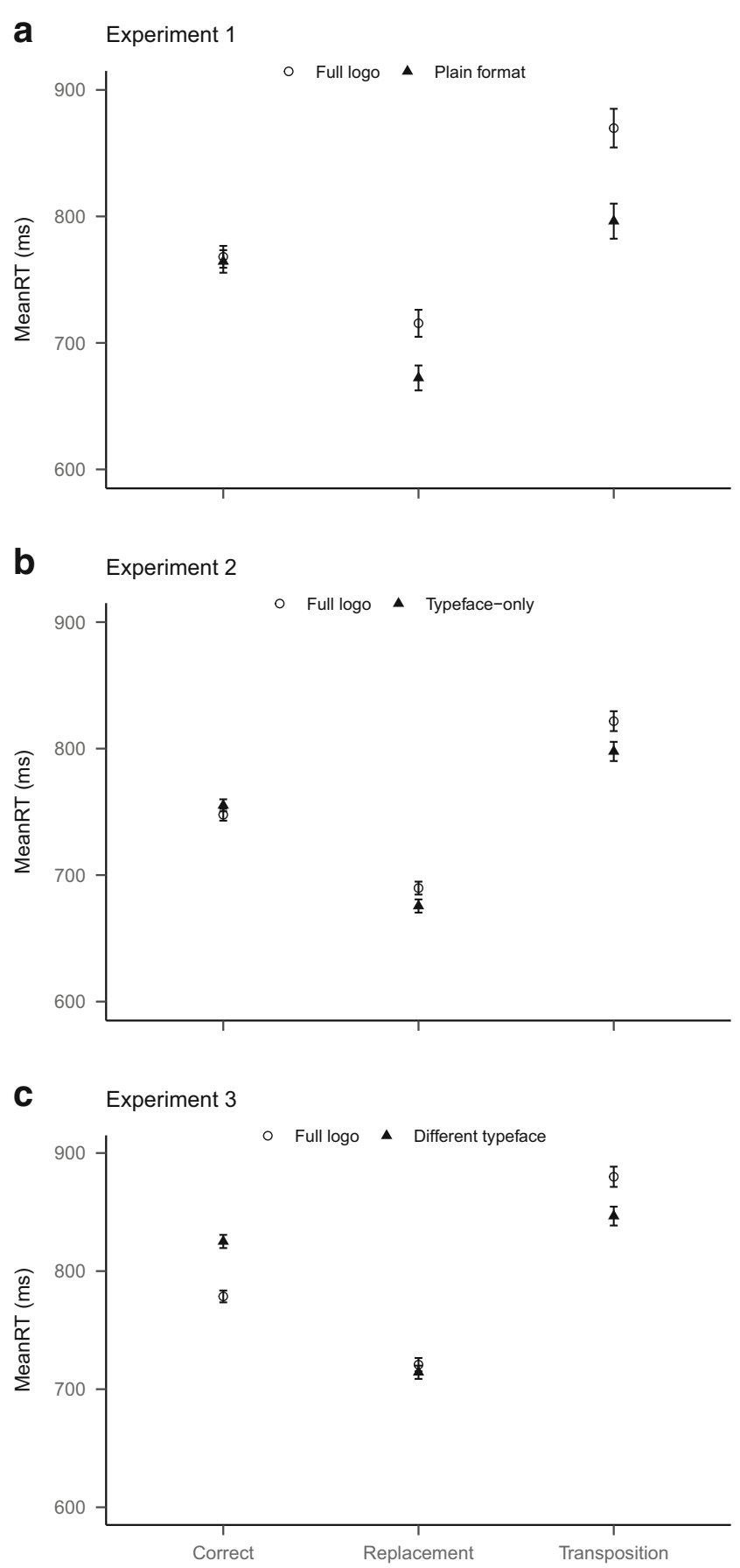

Fig. 2 Plots for the mean response times of the correctly spelled and misspelled items in Experiment 1 (a), Experiment 2 (b), and Experiment 3 (c). The error bars illustrate two standard errors above and below the mean

\section{Experiment 2}

Experiment 1 revealed that participants had more difficulty detecting misspelled brand names when presented in full logo format than when presented in plain format. The aim of Experiment 2 was to examine whether the higher confusability of the misspelled full logos was due to the style of lettering - as indicated earlier, typeface has been claimed to be a key element of a logo (Foroudi et al., 2017). Experiment 2 was similar to Experiment 1, except that the plain format was substituted by a format in which the logos were removed of all graphical information except letter style (typeface-only logos; see Fig. 1).

\section{Method}

\section{Participants}

The sample was composed of 80 students from the University of Valencia and the University of Málaga. ${ }^{4}$

\section{Materials}

They were the same as in Experiment 1, except for the substitution of three of the logos (Disney, Nescafé, STARBUCKS $\rightarrow$ pepsi, vodafone, Heineken). The reason was that the Disney and Nescafé logos are characterized by their style of lettering rather than by color/layout, and Starbucks' current logo only contains graphical information (i.e., it is a logomark). The logos and their transposed-letter/replacement-letter counterparts were presented either a format in which all graphical information was present (i.e., full logo) or in format that removed graphical information (layout and color) except letter style (i.e., typeface-only logo). The typeface-only stimuli were presented in gray (RGB code: R112/G112/B112; see Fig. 1) —none of the logos were originally presented in gray.

\section{Procedure}

The setup was the same as in Experiment 1, except that the task was programed using the Gorilla Experiment Builder (www.gorilla.sc) and presented online on the same platform (Anwyl-Irvine, Massonnié, Flitton, Kirkham, \& Evershed, 2019).

\section{Results}

The analyses were parallel to those in Experiment 1 . The averages latencies and accuracy per condition are presented in Table 2.

\footnotetext{
${ }^{4}$ Sample size was larger than in Experiment 1 to capture the presumably smaller effects due to the typeface-only format together because the experiment was conducted online rather than in the lab due to the COVID-19 outbreak.
} 
Table 2 Mean correct response times (in ms) and error rates (in percentage) for correctly spelled and misspelled brand names Experiment 2

\begin{tabular}{lllll}
\hline & Correct brand name & Transposed-letter brand name & Replacement-letter brand name & Transposed-letter effect \\
\hline Format & & & & \\
Full logo & $748(3.3)$ & $822(15.3)$ & $690(2.4)$ & $132(12.9)$ \\
Typeface only & $755(5.5)$ & $798(12.4)$ & $676(2.0)$ & $122(10.6)$ \\
\hline
\end{tabular}

\section{Misspelled items}

Results showed slower responses to transposed-letter items than to replacement-letter items, $b=164.63, S E=$ $1.96, t=83.97, p<.001$, and that misspelled typefaceonly logos were responded to more slowly than the misspelled full logos, $b=-16.31, S E=2.00, t=-8.14$, $p<.001$. Furthermore, the transposed-letter effect was greater for full logos than for misspelled typeface-only $\log 0$ (132 vs. $122 \mathrm{~ms}$, respectively; interaction: $b=$ $-10.59, S E=1.56, t=-6.79, p<.001$; see Fig. 2b).

The analyses of the accuracy data showed lower accuracy for transposed-letter logos than for replacement-letter $\operatorname{logos}, b=-1,94, S E=0.28, z=6.94, p<.001$. The other effects were not significant (both $z \mathrm{~s}<1$ ).

\section{Correctly spelled items}

Full logos were identified faster than the typeface-only logos, $b=-11.25, S E=1.79, t=-6.29, p<.001$. The accuracy data also showed some advantage of the full logos, but the difference only approached significance, $b$ $=0.27, S E=0.15, z=1.80, p=.073$.

\section{Experiment 3}

Experiment 2 showed that misspelled typeface-only logos produced a transposed-letter effect that was only slightly smaller than that produced by misspelled full logos. Furthermore, for correctly spelled items, typeface-only logos were identified nearly as fast as full logos. These findings reinforce the importance of the letter style in logos (see Foroudi et al., 2017). The goal of Experiment 3 was to examine the role of graphical information other than typeface in the identification of logos. To that end, Experiment 3 compared the full logo condition to a "different typeface" logo condition that kept the graphical information, except that the typeface was taken from another logo (see Fig. 1 for illustration).

\section{Method}

\section{Participants}

The sample was composed of 80 students from the University of Valencia.

\section{Materials}

The logos were the same as in Experiment 2. Both the logos and their misspelled counterparts were presented with all their corresponding graphical information (i.e., full logo) or in a format that only modified the typeface of the logo by using another logo's typeface (i.e., different typeface logo; e.g., amazon presented with Pepsi's typeface; see Fig. 1).

\section{Procedure}

It was the same as in Experiment 2

\section{Results}

The analyses were the analogous to Experiment 2. The mean RTs and accuracy per condition are shown in Table 3.

\section{Misspelled items}

Response times were slower to transposed-letter than to replacement-letter items, $b=192.46, S E=1.90, t=101.51$, $p<.001$, and responses times were slower to misspelled different typeface logos than to misspelled full logos, $b=-12.97$, $S E=2.24, t=-5.79, p<.001$. Importantly, the transposedletter effect was 26-ms greater for misspelled full logos than for misspelled different typeface logos (159 vs. $133 \mathrm{~ms}$, respectively; interaction: $b=-35.61, S E=1.87, t=-19.04, p<$ .001 ; see Fig. 2c).

The analyses of the accuracy data showed lower accuracy for transposed-letter logos than for replacement-letter logos, $b$ $=-1,96, S E=0.25, z=-7.70, p<.001$-this difference was greater for misspelled full logos than for misspelled different 
Table 3 Mean correct response times (in $\mathrm{ms}$ ) and error rates (in percentage) for correctly spelled and misspelled brand names Experiment 3

\begin{tabular}{lcccc}
\hline & Correct brand name & Transposed-letter brand name & Replacement-letter brand name & Transposed-letter effect \\
\hline Format & & & & \\
Full logo & $779(3.5)$ & $880(15.6)$ & $721(2.4)$ & $159(13.2)$ \\
Different typeface & $825(7.9)$ & $847(11.1)$ & $714(2.2)$ & $133(8.9)$ \\
\hline
\end{tabular}

typeface logos (13.2 vs. 8.9\%; interaction: $b=0.35, S E=0.15$, $z=2.36, p=.018)$.

\section{Correctly spelled items}

Full logos were identified faster than different typeface logos, $b=-52.83, S E=3.05, t=-17.3, p<.001$. The accuracy data also showed an advantage of the full logos, $b=0.63, S E=$ $0.16, z=3.92, p<.001$.

\section{General discussion}

We designed three experiments that examined whether the confusability of misspelled brand names (measured via the transposed-letter confusability effect) increases when presented with the graphical information of their corresponding logos relative to when presented in plain format (Experiment 1), when the logo was presented without graphical information other than letter style (Experiment 2), and when the logo was presented with all the graphical information, except letter style (Experiment 3). Results showed a sizeable transposed-letter confusability effect in the formats: transposed-letter items produced longer responses and more errors than replacement-letter items. More important, the transposed-letter confusability effect was larger for misspelled full logos than for misspelled plain brand names (a 30-ms difference; Experiment 1) and misspelled different typeface logos (a 26-ms difference; Experiment 3), whereas this difference was smaller for typeface-only logos (a 10-ms difference; Experiment 2) (see Fig. 2). ${ }^{5}$ Notably, the higher confusability of the misspelled full logos occurred in an orthographically based task ("Is the brand name spelled correctly?") in which the presence/absence of graphical information was not diagnostic of the response. In addition, for the correctly spelled logos, typeface-only logos (but not the different typeface logos) produced identification times nearly as fast as full logos. We now discuss the implications of these findings.

From the theoretical point of view, our findings rule out a simple generalization of orthographically-based models of word recognition (see Davis, 2010; Grainger, 2018) for logo

\footnotetext{
5 One might argue that the repeated presentation of the stimuli might have diminished the magnitude of the transposed-letter effects in the second half of the experiment. However, post hoc analyses failed to show any consistent effects across time.
}

identification. In these models, the abstract percept from a transposed-letter misspelled logo would be similar as that of the correctly spelled logo regardless of format (i.e., these models would have predicted a similar transposed-letter effect). Instead, the present findings strongly suggest that, when we encounter a logo, we process not only its orthographic information (i.e., letter identity/position) but also its graphical information (i.e., typeface, color, design). Importantly, our findings suggest that typeface appears to play a greater role when identifying a logo than other graphical elements such as color or design, thus offering empirical support to previous claims from marketing researchers (see Foroudi et al., 2017). We acknowledge, however, that further research is necessary to test whether the prevalent role of the typeface over other graphical elements of the logo (i.e., color/design) also occurs in more semantically based tasks (e.g., "Does the logo represents a brand name of a given category [e.g., travel]?").

Another theoretical implication of the increased magnitude of the transposed-letter effect when the logos kept all their visual characteristics is that we may not accurately encode the specific details that characterize highly familiar objects. Because we see them frequently in exactly the same layout, we do not need detailed information to access their stored representation. Indeed, in legal litigations on trademark similarity, a recurrent argument is that "the average consumer normally perceives a mark as a whole and does not proceed to analyse its various details" (\#35, Bimbo v. Panrico, 2014). Importantly, a growing body of research shows a lack of accuracy at recalling elements of other visual objects we encounter often in our daily lives. An excellent demonstration is the study of Blake et al. (2015), in which a large percentage of individuals could not identify the correct Apple logomark among a series of visually similar options. Parallel evidence has been shown with another type of commonly encountered visual object: letters. Wong, Wadee, Ellenblum, and McCloskey (2018) found that, despite their extensive experience, the vast majority of adult readers fail to recall the exact shape of the looptail of the letter $g$, even after performing a search task in which they had to identify an uppercase $G$ among multiple $g$ s. Taken together, these findings suggest that we have gaps in our knowledge about the specific details of visual objects that we encounter often.

From an applied point of view, our findings can be used to guide the decisions, on legal litigations, concerning whether a potential lookalike brand name is too similar to a well- 
established brand name. Our findings revealed that one would need to consider not only the names (i.e., whether they look or sound alike) but also the graphical information in which they are embedded. In particular, Experiment 2 revealed that typeface should also be considered as a relevant element when settling disputes on trademark similarity.

In sum, the present experiments showed that misspelled brand names are more difficult to detect as being fake when presented with its full graphical information than when these elements are not present. The take-home message is that the graphical distinctiveness of logos makes them easy to identify, but also make them vulnerable to counterfeits created by misspelling the brand name. Further research across various techniques is necessary to determine which graphical elements of logos make them more distinctive (typeface, color, or general design).

\section{Appendix}

\section{GLME model for the latency data in the experiments}

Experiment 1:

RT_GLME $=\operatorname{glmer}(\mathrm{RT} \sim \mathrm{TLRLc} *$ typec $+(1+$ TLRLc|item $)+(1+$ TLRLc*typec $\mid$ subject $)$, data = counterfeitRT, family = Gamma(link="identity"), control=glmerControl(optimizer="bobyqa", optCtrl=list(maxfun=2e5)))

Experiment 2:

RT _GLME $=$ glmer $(\mathrm{RT} \sim$ TLRLc*typec + $(1+$ TLRLc+ typec $\mid$ item $)+(1+$ TLRLc+typec|subject $)$, data $=$ counterfeitRT, family = Gamma(link="identity"), control=glmerControl(optimizer="bobyqa", optCtrl=list(maxfun=2e5)))

Experiment 3:

RT_GLME $=\operatorname{glmer}(\mathrm{RT} \sim \mathrm{TLRLc} *$ typec $+(1+$ TLRLc*typec $\mid$ item $)+(1+$ TLRLc |subject $)$, data $=$ counterfeitRT, family = Gamma(link="identity"), control=glmerControl(optimizer="bobyqa", optCtrl=list(maxfun=2e5)))

GLME model for the accuracy data in the experiments accuracy_GLME $=$ glmer(accuracy $\sim$ TLRLc*typec $+(1+$ TLRLc|item $)+(1+$ TLRLc $*$ typec|subject $)$, data = counterfeit, family $=$ binomial, control=glmerControl(optimizer="bobyqa", optCtrl=list(maxfun=2e5)))

\section{References}

Abdel-Khalik, J. (2007). Is a rose by any other image still a rose? Disconnecting dilution's similarity test from traditional trademark concepts. University of Toledo Law Review, 39(3), 591.

Anwyl-Irvine, A. L., Massonnié, J., Flitton, A., Kirkham, N., \& Evershed, J. K. (2019). Gorilla in our midst: An online behavioral experiment builder. Behavior Research Methods, 52(1), 388-407. https://doi.org/10.3758/s13428-019-01237-x

Bates, D., Maechler, M., Bolker, B., \& Walker, S. (2015). Fitting linear mixed-effects models using lme4. Journal of Statistical Software, 67(1), 1-48. https://doi.org/10.18637/jss.v067.i01

Bimbo V. Panrico (2014). Case R C-591/12: Court of Justice of the European Union. http://curia.europa.eu/juris/document/document. jsf?text=\&docid=151966. Retrieved on June 8, 2020

Blake, A. B., Nazarian, M., \& Castel, A. D. (2015). The Apple of the mind's eye: Everyday attention, metamemory, and reconstructive memory for the Apple logo. Quarterly Journal of Experimental Psychology, 68(5), 858-865. https://doi.org/10.1080/17470218. 2014.1002798

Butler, S. (2017). Yoko Ono halts sale of John Lemon lemonade. The Guardian. https://www.theguardian.com/business/2017/sep/19/ yoko-ono-john-lemon-lemonade-copyright. Accessed 8 June 2020

Chang, J. (2014). Trademark counterfeiting in China: The real price of knock-offs. Santa Clara Law Review, 54(3), 765-790.

Clear, M. (2013). Own-label 'copycat' products: Can you spot the difference? Which? https://www.which.co.uk/news/2013/04/own-labelcopycat-products-can-you-spot-the-difference-316370. Retrieved on June 8,2020

Davis, C. J. (2010). The spatial coding model of visual word identification. Psychological Review, 117(3), 713-758. https://doi.org/10. 1037/a0019738

Davis, C. J., \& Perea, M. (2005). BuscaPalabras: A program for deriving orthographic and phonological neighborhood statistics and other psycholinguistic indices in Spanish. Behavior Research Methods, 37, 665-671. https://doi.org/10.3758/bf03192738

Foroudi, P., Melewar, T. C., \& Gupta, S. (2017). Corporate logo: History, definition, and components. International Studies of Management \& Organization, 47, 176-196. https://doi.org/10.1080/00208825. 2017.1256166

Forster, K. I., \& Forster, J. C. (2003). DMDX: A windows display program with millisecond accuracy. Behavior Research Methods, Instruments, and Computers, 35, 116-124. https://doi.org/10.3758/ BF03195503

Gontijo, P. F. G., \& Zhang, S. (2007). The mental representation of brand names: Are brand names a class by themselves? In T. M. Lowrey (Ed.), Psycholinguistic phenomena in marketing communications (pp. 23-37). Erlbaum.

Grainger, J. (2018). Orthographic processing: A "mid-level" vision of reading. Quarterly Journal of Experimental Psychology, 71(2), 335-359. https://doi.org/10.1080/17470218.2017.1314515

Kuby, P., Aldridge, J., \& Snyder, S. (1994). Developmental progression of environmental print recognition in kindergarten children. Reading Psychology, 15(1), 1-9. https://doi.org/10.1080/ 0270271940150101

Masonheimer, P. E., Drum, P. A., \& Ehri, L. C. (1984). Does environmental print identification lead children into word reading? Journal of Reading Behavior, 16(4), 257-271. https://doi.org/10.1080/ 10862968409547520

Marcet, A., \& Perea, M. (2018). Can I order a burger at rnacdonalds.com? Visual similarity effects of multi-letter combinations at the early stages of word recognition. Journal of Experimental Psychology: Learning, Memory, \& Cognition, 44(5), 699-706. https://doi.org/ $10.1037 / x \operatorname{lm} 0000477$

O’Connor, R. E., \& Forster, K. I. (1981). Criterion bias and search sequence bias in word recognition. Memory \& Cognition, 9, 78-92. https://doi.org/10.3758/bf03196953

OECD. (2019). Trends in trade in counterfeit and pirated goods [Illicit Trade series]. https://doi.org/10.1787/26175835

Pathak, A., Velasco, C., \& Calvert, G. A. (2019a). Identifying counterfeit brand logos: On the importance of the first and last letters of a logotype. European Journal of Marketing, 53(6), 2109-2125. https://doi.org/10.1108/ejm-09-2017-0586 
Pathak, A., Velasco, C., \& Calvert, G. A. (2019b). Implicit and explicit identification of counterfeit brand logos based on logotype transposition. Journal of Product \& Brand Management, 28(10). https:// doi.org/10.1108/jpbm-06-2018-1921

Perea, M., \& Lupker, S. J. (2004). Can CANISO activate CASINO? Transposed-letter similarity effects with nonadjacent letter positions. Journal of Memory and Language, 51(2), 231-246. https://doi.org/ 10.1016/j.jml.2004.05.005

Perea, M., Duñabeitia, J. A., \& Carreiras, M. (2008). Transposed-letter priming effects for close versus distant transpositions. Experimental Psychology, 55(6), 384-393. https://doi.org/10.1027/1618-3169.55. 6.384

Perea, M., Jiménez, M., Talero, F., \& López-Cañada, S. (2015). Lettercase information and the identification of brand names. British Journal of Psychology, 106, 162-173. https://doi.org/10.1111/bjop. 12071

Peressotti, F., Cubelli, R., \& Job, R. (2003). On recognizing proper names: The orthographic cue hypothesis. Cognitive Psychology, 47(1), 87-116. https://doi.org/10.1016/s0010-0285(03)00004-5

Qiao, F., Chicotsky, B., \& Billings, A. C. (2016). Loving "Mapple Store" but Hating "Sprawl-Mart": A case study of brand parodies in The Simpsons. KOME-An International Journal of Pure Communication Inquiry, 4(1), 69-83. https://doi.org/10.17646/ kome.2016.15

Scaltritti, M., Dufau, S., \& Grainger, J. (2018). Stimulus orientation and the first-letter advantage. Acta Psychologica, 183, 37-42. https:// doi.org/10.1016/j.actpsy.2017.12.009

Share, D. L., \& Gur, T. (1999). How reading begins: A study of preschoolers' print identification strategies. Cognition and Instruction, 17(2), 177-213. https://doi.org/10.1207/s1532690xci170202

Tydgat, I., \& Grainger, J. (2009). Serial position effects in the identification of letters, digits, and symbols. Journal of Experimental Psychology: Human Perception and Performance, 35(2), 480 498. https://doi.org/10.1037/a0013027 van Horen, F., \& Pieters, R. (2012). Consumer evaluation of copycat brands: The effect of imitation type. International Journal of Research in Marketing, 29(3), 246-255. https://doi.org/10.1016/j. ijresmar.2012.04.001

Wong, K., Wadee, F., Ellenblum, G., \& McCloskey, M. (2018). The devil's in the g-tails: Deficient letter-shape knowledge and awareness despite massive visual experience. Journal of Experimental Psychology: Human Perception and Performance, 44(9), 1324 1335. https://doi.org/10.1037/xhp0000532

Yang, H., \& Lupker, S. J. (2019). Does letter rotation decrease transposed letter priming effects? Journal of Experimental Psychology: Learning, Memory, and Cognition, 45(12), 2309-2318. https://doi. org/10.1037/xlm0000697

Author note This research has been partly supported by Grants RED2018-102615-T and PSI2014-53444-P (M.P.) from the Spanish Ministry of Economy and Competitiveness and Grant GV/2020/074 (A.M.) from the Department of Innovation, Universities, Science and Digital Society of the Valencian Government.

Open practices statement

The data for the experiments is available (https://osf.io/m34zf/). The R scripts for the statistical models are available in the Appendix. All the stimuli (correctly spelled logos, misspelledlogos) and R scripts for data analyses are in the above OSF link. None of the experiments was preregistered.

Publisher's note Springer Nature remains neutral with regard to jurisdictional claims in published maps and institutional affiliations. 